\title{
THE DARK SIDE OF CHRISTMAS
}

\section{Incarceration and Alienation in Gabrielle Brady's film Island of the Hungry Ghosts (2018)}

[Received January 14th 2019; accepted February 15th 2019 - DOI: 10.21463/shima.13.1.14]

Philip Hayward

University of Technology Sydney <prhshima@gmail.com>

\section{Introduction}

Christmas Island is located 350 kilometres south of Jakarta and 1,400 kilometres north-west of the mid-north coast of the state of Western Australia (Figure 1) and has a land area of 165 square kilometres. The island's history of human inhabitation is comparatively shallow, commencing in 1899, shortly after it was claimed by the United Kingdom, the merchantadventurer George Clunies-Ross began to exploit its considerable phosphate deposits by importing indentured labourers from Malaya, Singapore and China (see Hunt, 2011). Initially administered by the Clunies-Ross family and British colonial authorities in Singapore, the island was transferred to Australian control in 1958 and since 1997 - together with the Cocos [Keeling] Islands - has formed part of Australia's Indian Ocean Territories. The cultural and linguistic diversity of the island's population is highly distinct within Australia on account of the prominence of individuals with non-European ancestry within its community. Of its population of 1843 (2016 Australian Bureau of Statistics census figures), 61.5\% were born outside of Australia. 21.1\% identify as being of Chinese ancestry, $12 \%$ Malay and 25.9\% claim Australian, English or Irish ancestry. These census figures merit comment in that for all they may represent the population of Christmas Island at the date of census, a hidden aspect of ABS statistics is the proportion of those surveyed who were temporary residents at time of census. ${ }^{1}$ With regard to the continuing and/or multi-generational population of the island, those of Chinese and Malay ancestry are the most prominent, with traces of their 120-year involvement with the island being present in its material and folkloric history.

For all that the island's mining history has served to sustain a continuing community, it has also scarred substantial areas of the island, removing its topsoil and leaving areas of stark, exposed limestone that have been largely unremediated and have been largely over-run by invasive weeds. Since 2006 the island has also been home to internment camp. The initial impetus to establish this facility - officially termed an "immigration reception and processing centre" - resulted from the arrival of a number of boats from Indonesia carrying asylum seekers from various parts of Asia and the Middle East and the necessity of temporarily housing them while their applications were subject to initial assessment. This operation assumed a prominent place in national politics in 2001, immediately prior to general elections, when the Liberal Party created a scare campaign about the number of asylum seekers attempting to arrive in Australia's Indian Ocean and Timor Sea territories by boat. Successfully exploiting this angle, the subsequent Liberal/National Party coalition

\footnotetext{
${ }^{1}$ Many being employed on fixed term contracts or working on the island on other short-term bases.
} 
Government introduced measures to excise Christmas and the Cocos (Keeling) Islands (and other offshore areas $^{2}$ ) from Australia - with regard to national obligations to consider applications for asylum from those entering its territory - and to set up holding and processing facilities on Christmas Island and, by agreement with external countries, on Manus Island (Papua New Guinea) and in Nauru. The most immediate impact of this policy on Christmas Island was the development of a major detention centre in the central area of the island capable of housing 800 individuals (and constructed at a cost of over $\$ 400$ million and costing c $\$ 30$ million p.a. in operating costs). This also distorted the island's economy and social make-up by bringing in a considerable number of construction, maintenance and security workers (visibly/anecdotally of European ancestry) who required accommodation and various types of facilitation.

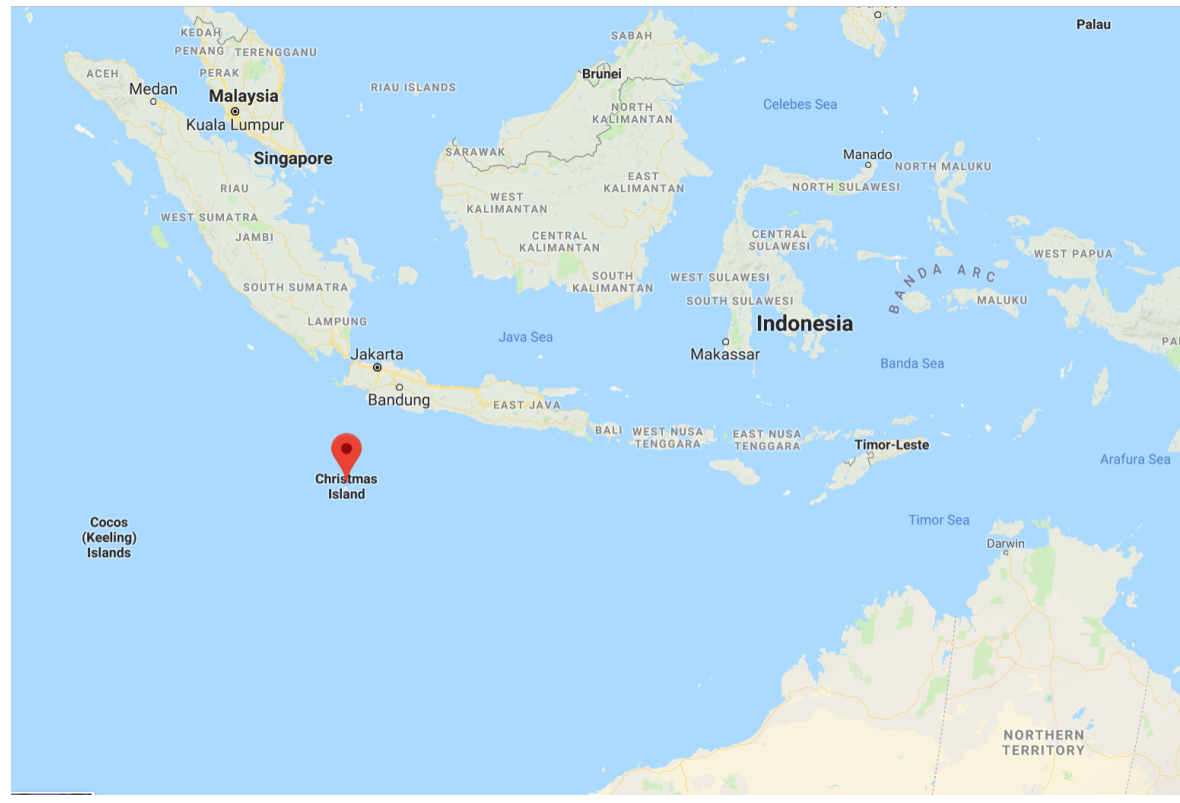

Figure 1 - Position of Christmas Island in relation to Indonesia and Australia (Google Maps, 2019)

The pressure on accommodation and on securing seats on incoming and outgoing flights to the island also impeded development of a relatively new industry, tourism. While there was short-lived period of gambling-related tourism in 1993-1998, when the Christmas Island Resort operated, more recent developments of tourism have been oriented to the island's environment - or, rather, those areas of the island that have escaped the adverse impact of mining operations. The natural vegetation of Christmas Island comprises primary and marginal rainforest, including 17 unique endemic species, on its central plateau and surrounding slopes and its interior is home to two distinct (and now iconic) species of crustacean, the red crab (Gecarcoidea natalis) and the coconut/robber crab (Birgus latro). The former is known for its multitude, swarming across the island and interrupting traffic during the October-November wet season and the latter is the world's largest living invertebrate. The island is also a mecca for ornithologists on account of its various types of

\footnotetext{
${ }^{2}$ Together with the Ashmore and Cartier Reefs in the Arafura Sea.
} 
frigate (frigata) and booby (sula) birds and the golden bosun (Phaethon lepturus fulvus). Concern about the damage being done to these species by mining activities led first to the appointment of a government conservator, in 1977, and then the declaration of a national park site on the Egreria Point in 1980 that was expanded to encompass $63 \%$ of the island in 1989. While marginalised by the imposition of the detention centre and its staff, environmentally-focussed tourism has established a foothold in Christmas Island's economy and is currently being promoted as a successor industry to both the detention centre and the phosphate mining industry. ${ }^{3}$

Gabrielle Brady's hybrid drama-documentary film takes three filaments from the complex modern history sketched above. The primary one concerns the experiences of those incarcerated on the island and those employed to assist them manage their trauma. This is interwoven with intersecting and variously complementary explorations of the island's natural environment and of the customs and beliefs of Christmas Islanders of Chinese descent. The following section analyses these aspects of the film and its overall textual operation.

\section{Insular Spaces/ Compelling Testimonies}

While notionally separate - and even antithetical - the division between documentary and fiction film making has always been blurred and a number of film-makers have developed various styles of poetic, impressionistic, expository, reflexive and/or otherwise experimental documentaries at various historical junctures (see Kahana [ed], 2016). The genre known as docudrama (or documentary-drama), which is wholly or partly based on the staging of sequences that adhere closely to actual events and interactions, is also well established (see Paget, 2011). In recent years work based on one or more of these approaches have been referred to as "hybrid documentaries" (Lipkin, 2002; Landesman, 2008). One element that has been key to many productions of this type has been the film maker's desire to inform audiences about actual conditions and socio-political issues in an engaging and persuasive manner. Island of the Hungry Ghosts exemplifies this hybridity by blending documentary footage with re-enactments of scenes that took place on the island by those involved and short drama sequences. As subsequent discussions identify, this hybridity was as much a pragmatic decision as an aesthetic one.

The Christmas Island represented on-screen by Brady is largely an insular - and often claustrophobic - space comprising small rooms where counselling takes place, roadways and paths across the island and dense tangles of vegetation that various characters traverse and/or slash their way through. With one exception (detailed below) the coastline of the island is absent from the film until the final scenes when the lead character, Poh Lin Lee, goes down to a narrow, isolated beach with her daughter, Poppy, to mark the end of their time on the island and her engagement with its internees (Figure 2). The major port facility and small commercial and recreational strip around and to the east of Flying Fish Cove are entirely absent, unseen by the viewer just as they are unseen by the internees who have been flown into the island and then confined to the camp in its interior.

\footnotetext{
${ }^{3}$ The island's mining operations have recently been denied permission to access crown land to mine previously unexploited deposits by the Australian Government on account of its likely impact upon the very indigenous flora and fauna that has been the key focus of tourism promotion (Diss, 2018).
} 


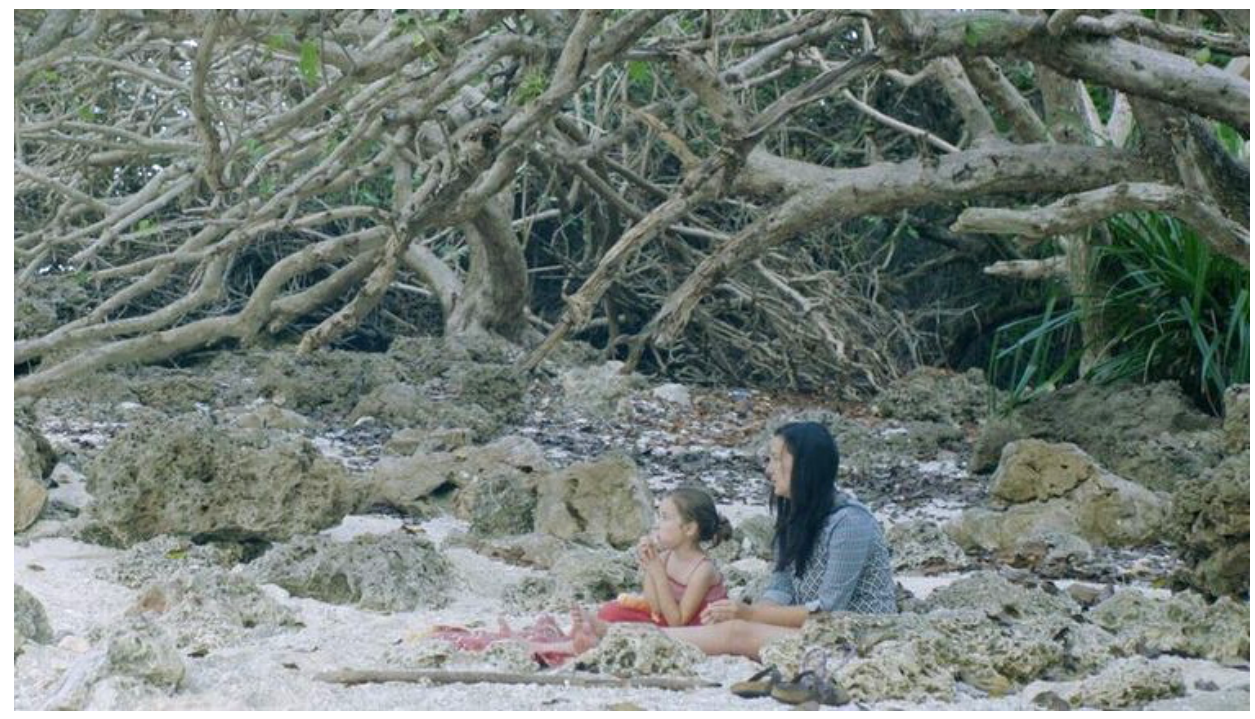

Figure 2 - Poh Lin Lee and her daughter Poppy in their final beach scene from Island of the Hungry Ghosts

The film is slow-paced, giving the internees time to relate the intensely alienating and dehumanising treatment given to them by the camps as they talk to former camp trauma therapist Lee (effectively 'playing herself). One of the key techniques that Lee is shown to utilise is "sandplay therapy" a well-established technique that the Australian Psychology Today online resource describes as:

a nonverbal, therapeutic intervention that makes use of a sandbox, toy figures, and sometimes water, to create scenes of miniature worlds that reflect a person's inner thoughts, struggles, and concerns [that] is practiced along with talk therapy, using the sandbox and figures as communication tools. (nd: online)

Lee (2018) identifies that her particular approach to sandplay involves combining it with "narrative practice" "in response to the multiple, ongoing trauma and injustice faced by people seeking asylum in Australia" (2018: 1). Characterising her approach as a poststructuralist one (ibid), she conceives it as offering "a therapeutic practice that intends to counter the effects of restriction, limited choice, agency and movement" (ibid). Her sandplay sessions with internees constitute the poignant visual core of the film as traumatic experiences are suggested by the therapy clients' arrangements of these figures (Figure 3) the apparent inconsequentiality of manipulating toys in a sand box underlining our inability to grasp the forceful events that the clients' recall. Further pathos is generated in one session when Lee identifies that she has sourced the fine white sand from an island beach that the internees have never (and will never) see. These scenes also generate a poetic and saddening coda to the film as Lee comes to the realisation that she cannot continue her counselling due to both its impact upon her and her perception that her practice is effectively propping up the detention camp system. Packing up her tools-of-trade she leaves her office and takes the sandbox down to a beach on the north-east corner of the island, wades into the sea and slowly pours the sand back into the waves. 


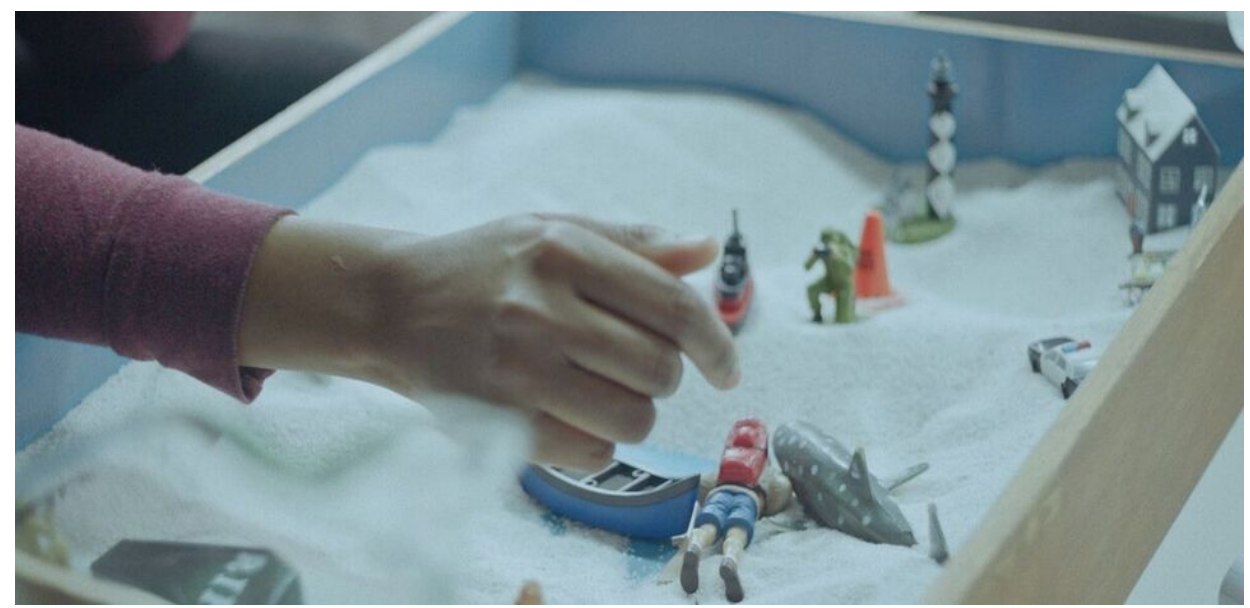

Figure 3 - A sandbox scene from Island of the Hungry Ghosts

The therapy sessions are poignant and painful, slowly revealing the systemic inhumanity of internment and the series of measures that have undermined internees' senses of self-worth and of hope. The scenes convey a strong sense of authenticity of experience on the part of both the therapy clients and therapist that derives from the particular process by which they generated. As Lee has explained:

initially we started by filming the therapy sessions whilst we were on the island with people who wanted to participate in the project but very quickly Gabrielle and I found it ethically outside of our intention i.e. guards outside the room, people going back into detention after the session and then we couldn't be in contact for a period of time so we could not ensure people's safety and care after sessions and I found that under the risks of being 'found out' it meant that therapy was compromised...

So, Gabrielle and I and the people decided together to make the film project a lot longer (time wise) and when some of the people were transferred to the mainland we met with them on the mainland (Melbourne) re-created the therapy room and then held therapeutic sessions. This was the part of the film where Gabrielle stepped back as director and the agreement was that it was first therapy and then if it contributed in some way to the film it would be used (with people's explicit permission). So the conversations are not re-creations of previously held conversations instead people brought to these conversations what was most present that they wanted to talk about (no direction or scripting).

In addition to providing moving confirmation of the deep trauma the clients experienced on Christmas Island, the sessions produce one of the few overtly political statements in the film. This occurs when Lee responds to one of her client's characterisations that she arrived in Australia illegally (and thereby deserves internment) by gently correcting her and informing her that there is nothing illegal about arriving in any country and claiming asylum. This sequence has a dual meaning and impact. Within the film, it ameliorates the 
sense of guilt that the internee has been made to feel through her experience and stresses the blatantly discriminative treatment she has had from the Australian Border Force services. More broadly it corrects the continuing reference to asylum seekers arriving by sea as "illegal immigrants" by many Australian politicians. The impact of these testaments upon the audience is amplified by the mounting distress of the councillor, who not only has to hear these stories and try to support and comfort the tellers, but who is also shown dealing on the phone with camp authorities who remove inmates in an arbitrary manner and are bound by secrecy to withhold all but the vaguest facts about their plight.

Lee's character - as manifested in the film's diegesis (where actual biographical details are not provided) is ambiguous. Her name and appearance indicate Chinese ancestry but, with her French husband and bilingual daughter, she is set apart from the island's Chinese community. In this regard, she stands somewhere between the Australia that oppresses the inmates - that is, a modern multi-cultural Australia that has remained unable to shake the conservative, white and inherently racist domination of federal politics ${ }^{4}$ - and the Chinese Malay population of Christmas Island, who have their own distinct culture.

The film provides a notable reflection of the manner in which the Chinese-descended population of Christmas Island have lived, worked, worshipped and relaxed in a novel landscape. As the film reveals, they have culturally acclimatised in a manner that is informed by traditional Chinese beliefs and folklore and have come to perceive particular locations as inhabited by spiritual entities. One example of the latter is a local belief that the sea goddess Ma Chor (more commonly known across South-East Asia as 'Mazu') resides in a specific location off the shore of the island. Traditionally this was perceived to be in an isolated and inaccessible area near the eastern corner of what is now the (inoperative) Christmas Island Resort. A small shrine was constructed there some time in the mid zoth Century and was visited at various points in the year in order to make offerings to her. When coastal land was sold to Perth developer Frank Woodmore in 1985 it became evident that the owners wished to prevent access to the shrine and, following a period of dispute, a compromise was reached whereby the resort paid for the construction of a new temple on the coast just to the west of the resort. The process illustrated both the strong sense of association of mythology and place by the Chinese-descended population and their pragmatism at being able to negotiate disruptions to their traditional spatial and spiritual practices by external agencies (arguably the key characteristic of a resilient and organic culture).

While the story of Ma Chor is not referenced by the film, another traditional tale is: that of a dragon that supposedly swam to Christmas Island from China sometime in the late $1800 \mathrm{~s}$ (around the time the first Chinese workers arrived) and took up residence in a cave where it remains to this day (and with the noise of waves crashing into coastal blow-holes being interpreted as the dragon's roar). This tale is recounted in the film by Lee's husband, Arthur, to his daughter, Poppy, as a bedtime story. This minor plot element provides a point of connection between Lee and her family and the Chinese-descended population, which she is not shown as interacting with. The film takes its title from the annual 'Hungry Ghost' festival (also referred to in China as 'Zhongyuan Jie'), when the deceased are believed to be able to visit the living and are appeased and venerated by them by means of various offerings. Failure to adequately cater for them is seen to bring ill-fortune. The festival is an official holiday on Christmas Island, usually falling in August, and is one of the island's major

\footnotetext{
${ }^{4}$ Fittingly, in this regard, Lee is an Australian of partial Malay Chinese descent.
} 
celebrations of Chinese ancestry and heritage. The film shows various aspects of the festival, including the burning of devotional materials and of rice in wire containers. One notable sequence shows a middle-aged couple negotiating an overgrown path through dense bush to a remote gravesite where some of the first workers are buried. The couple collaborate in their progress, with the woman chanting to appease the ghost spirits while the husband attempts to clear the way. Finally reaching the graves (which do not bear their occupants' names), the couple reverently acknowledge the forgotten workers who died so far from their homelands. The scene notably "rhymes" with another towards the conclusion of the film. Oppressed and disenchanted by her work, Lee is shown out in the bush, hacking at a path to make progress across the terrain. After some effort she finally comes to the top of an escarpment, looking north-west towards the coast. The screen shows the view she sees, of a massive camp set in the landscape and abruptly delineated by straight fences and access roads.

The scene described above has been identified by Brady as one based on a similar experience she had that inspired the film itself:

At that time asylum seekers were still allowed out of the centre for short afternoon trips around the island usually just once every six months or so. And on one of these trips I went along and was able to meet three young guys from Afghanistan. There was immense relief that they were out of the centre for the afternoon and they were in high spirits. They shared jokes and songs. They were actually seeing the island for the first time even though they had been there for over a year. When they were taken back to the centre there was just a very deep and heavy silence. It was so hard to let them go and not be able to do anything about it. After this Poh took me to one of the remote jungles. We cut our way through the growth. And at the look out, down below, for the first time, I could see the enormous high security detention centre. Imagining these young guys I had just met back in this anonymous and looming place was terrifying. I was lost for words. The stark contrast of the beauty I had experienced on the island and then this kind of horror I saw in front of me really marked me along with the atmosphere and strangeness of the island. (BFI Press Kit, 2017: 4)

The "atmosphere" and "strangeness" that Brady refers to represent the convergence of a number of facets of Christmas Island. The sprawling high security centre, its secretive operatives and the flights in and out of the island's airport create an air of mystery and foreboding. Similarly, the disturbed landscape in and round mining areas and the large trucks that career down unmade roads are unsettling. And framing these, the densely entangled vegetation of the island's rainforest is home to the previously mentioned crustaceans that swarm over roads (Figure 4), causing closures and requiring rangers to manage traffic so as to prevent the carnage that would follow from trucks and cars driving over them. The sheer number of red crabs on the island suggests human presence to be secondary and the rangers who ensure their safety in the film show a compassion for crustaceans that is in poignant contrast to the lack of compassion shown to human inmates of the island's processing facilities. In several sequences, especially those in which the sound of the red crabs in transit is placed high in the mix, there is a sense in which the island is the crabs' domain and humans are recent interfering players in an ecological system that is alien to them. 


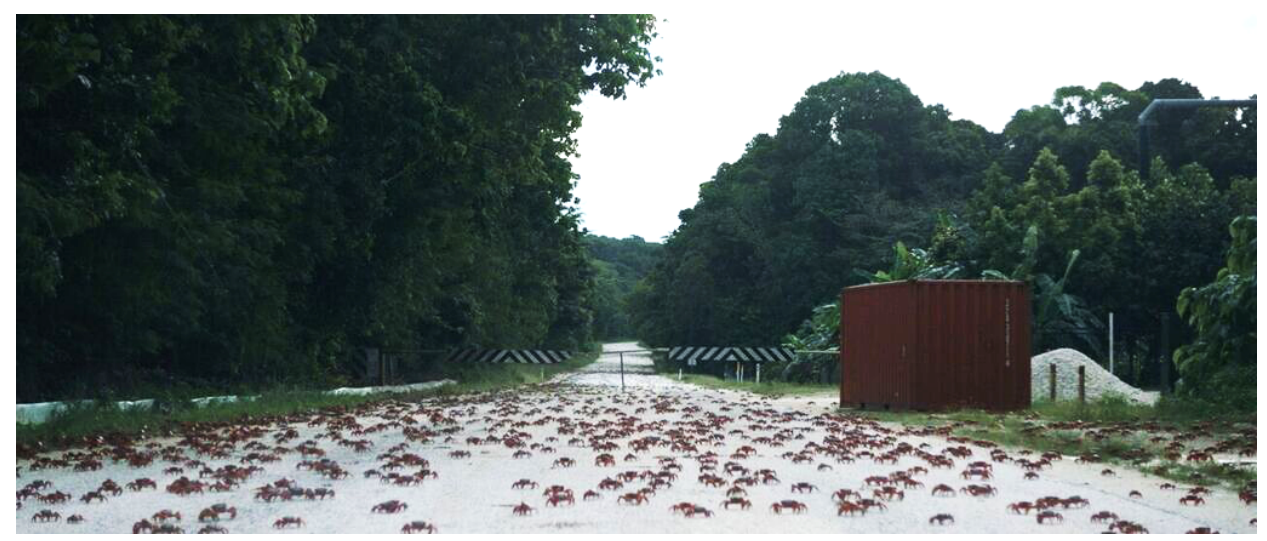

Figure 4 - Swarming crabs in Island of the Hungry Ghosts

Island of the Hungry Ghosts does not attempt to provide a definitive account of either the nature and history of the island's internment camp or of Christmas island's society and culture more generally. Rather, it draws on these to create a crucible in which the experiences and emotional trauma of a group of internees and their therapist can be presented and perceived. In this manner, the film is analogous to its central therapy motif the sandbox in which figures are deployed to prompt raw and honest experiences of trauma in a safe space. And like such therapy sessions, the film's impact resides in the presentation of the experiences of those who are rendered invisible by state power, incarceration and silencing.

Thanks to Poh Lin Lee for her responses to questions of the production of the film.

\section{BIBLIOGRAPHY}

Australian Bureau of Statistics (2016) '2016 Census QuickStats - Christmas Island': http://quickstats.censusdata.abs.gov.au/census_services/getproduct/census/2016/quicksta t/SSC9oooı\#cultural - accessed 11th January 2019

BFI (2017) BFI Press Kit for Island of the Hungry Ghosts

Diss, K (2018) 'Christmas Island Facing Economic Collapse as mine expansion rejected to save red crabs', $A B C$ News 1st June: https://www.abc.net.au/news/2018-05-31/proposal-toexpand-christmas-island-phosphate-mine-knocked-back/9820382 - accessed 11th January 2019

Hunt, John (2011) Suffering through strength: the men who made Christmas Island, Canberra: self-published

Kahana, J (ed) The Documentary Film Reader: History, Theory, Criticism, Oxford: Oxford University Press 
Landesman, O (2008) 'In and out of this world: digital video and the new hybrid documentary', Studies in Documentary Film v2 n8: 33-45

Lee, P.L (2018) 'Narrative Practice and Sandplay: Practice-based stories of collaboration with people seeking asylum held in mandatory detention', Journal of Systemic Therapy v7 n2: 1-16

Lipkin, S.N (2002) Real emotional logic: Film and television docudrama as persuasive practices, Carbondale: Southern Illinois University Press

Paget, Derek (2011). No Other Way to Tell It: Dramadoc/docudrama on television (2nd edition) Manchester: Manchester University Press

Psychology Today (nd) 'Sandplay Therapy': https://www.psychologytoday.com/au/therapytypes/sandplay-therapy - accessed 1oth January 2019 